\title{
Establishing the Preponderance among the Challenges Facing the Implementation of Online Learning in Higher Learning Institutions
}

\author{
Hassan Seif \\ College of Informatics and \\ Virtual Education, \\ The University of Dodoma \\ Dodoma, Tanzania
}

\author{
Leornard J. Mselle \\ College of Informatics and \\ Virtual Education, \\ The University of Dodoma \\ Dodoma, Tanzania
}

\author{
Justunian Anatory \\ College of Informatics and \\ Virtual Education, \\ The University of Dodoma \\ Dodoma, Tanzania
}

\begin{abstract}
Advancement in Information and Communication Technology (ICTs) can be used to improve delivery of education in higher learning institutions, especially in poor countries. Numerous universities in the world are turning to the use of ICTs to improve the provision and quality of education. Despite these facts, the situation in Tanzania is different. A number of factors have been named as contributors to the ineffective use of ICTs in university education. This study resurveys the main intervening factors. Using the method of logical analysis to derive their course-effect relationships, the direction towards improving the situation is suggested. It was found that, the main obstacle to effective adaptation of online learning in Higher Learning Institutions (HLIs) is the lack of awareness, which leads to lack of management support and poor policy which leads to general neglect of the approach.
\end{abstract}

\section{General Terms}

ICT for Education

\section{Keywords}

ICT, Internet, Learning management system, Online learning

\section{INTRODUCTION}

The use of ICTs is rapidly becoming wide spread throughout Higher Learning Institutions worldwide [1]. UNESCO policy paper for change and development in higher education urges higher education institutions to make greater use of the advantages offered by the advancement of ICT to improve the provision and quality of education [2]. Despite the technological advancement, the use of ICTs in Tanzanian higher education institutions is still very low [3]. Currently very few educational institutions have computer laboratories and multimedia facilities.

UDOM is made of six colleges namely; College of Education (CoED), College of Humanities and Social Sciences (CHSS), College of Informatics and Virtual Education (CIVE), College of Natural and Mathematical Sciences (CNMS), College of Health and Allied Sciences (CHAS) and College of Earth Sciences (CoES). In one academic year UDOM total numbers of students is well above 15,000 . These students in different colleges have to share some subjects, lecturers and learning materials. Under such conditions, Learning Management System (LMS) would have been a preferred means for content delivery. Taking MOODLE as an example, the status of online learning at UDOM is still in infancy. Observation has shown that that, there are very few instructors currently using MOODLE as their LMS. Fig. 1 depicts the number of course(s) registered on UDOM LMS. Data shows that there are only 8 courses from CIVE and 1 course from CoED and CoHAS. The use of ICTs for educational purposes does end with LMS. ICTs are useful for virtual laboratories in those cases where materials and reagents are scare or too expensive. Delivery of digital lectures for those subjects with few or inexperienced instructors is another track for ICTs exploitation in education. All these obvious advantages have not been harnessed despite the heavy demand and easy of adaptation. Very little is known of why the situation has remained so.

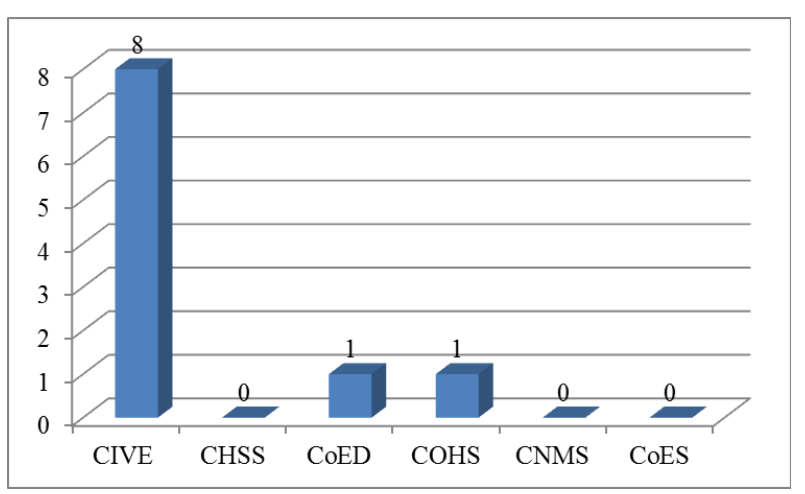

Fig. 1: Bar chart showing the number of course(s) registered on UDOM LMS

\section{RELATED WORKS}

Rais and Hashim [4] contend that, some of the factors that hinder the successful implementation of online learning include; poor accessibility of the Internet, lack of funds, lack of capacity for maintenance of the system infrastructure, poor selection of appropriate hardware and software, lack of technical skills and support, lack of top management support, lack of course-ware design and development team, lack of pedagogical skills, lack of training for lecturers, students and support staff and poor e-learning networks (LAN, WAN, Internet).

Abdul Razak et al. [5] report that, the main challenges facing the implementation and governance of e-Learning include the shortage of manpower and the lack of incentives for those involved in implementing e-Learning in HLIs. In addition, other challenges include; lack of a clear e-Learning policy, and lack of a clear line of responsibility on the task of planning and implementing e-Learning. Abdul Razak et al. [5] conclude that about $(26.9 \%)$ of HLIs feel that the absence of a dedicated e-Learning centre/unit/department is one of the 
main challenges.

Hussin et al. [6] contend that; moderate levels of motivation among the teaching staff and low attendance during training are the major challenges for e-Learning implementation. Other challenges include lack of expert trainers, lack of training modules, and unsuitable training schedules.

Rais et al., [4], Abdul Razak et al., [5] and Hussin et al [6] seem to agree that; lack of technical skills and support, and lack of top management support are the main challenges facing the implementation of online learning in the HLIs.

Unwin [7] argues that; key constraints in seeking to implement and develop e-learning strategies and practices, include: lack of infrastructure (particularly connectivity, and especially in rural areas), need for appropriate training and capacity development, lack of relevant digital content, and the cost of implementation.

Lujara [9] concludes that; access to electricity is the major limitation to the development of e-learning content and delivery for self-learning environment in Tanzania. This is because most of the rural areas have no power from national grid.

For solution, Gunga and Ricketts [8] suggest collaboration networks that include e-Learning sponsors, policy makers, telecommunication network service providers and educators as a means to solve the problems of online education in Africa. It means that the needs of e-Learning environments require multi stakeholder networks to share expertise and resolve issues related to training needs.

From this literature, there is a myriad of challenges on the adaptation of e-learning in HLIs. There is no one agreed starting point where the energy should be focused in order to make a break through.

\section{OBJECTIVES OF THE STUDY}

A number of universities around the world have successfully embraced e-Learning as a method for course delivery. This has turned online education into alternative or at least a considerable supplement to traditional mode of teaching and learning [10]. In most HLIs in Tanzania, online education is increasingly being talked about as a means for expanding and extending opportunity for massification of tertiary education under affordable cost.

Despite the fact that Tanzanian universities especially UDOM is in need of using online learning, in general this approach has not been effectively embraced. Since online learning has proved to be cost effective and quality improver, the quick adoption of this approach especially among poor nations such as Tanzania would be an enormous opportunity. Delay and ultimate failure to move fast is tantamount to wastage of a precious opportunity.

There is no consensus among researchers, on which factor or group of factors is more preponderant. There is no evidence of a study to focus on the factor that may be the root course of the problem. Discovery and discussion of such factor and its preponderance can help policy makers to focus on the most prominent factor in order to improve the use of ICTs in HLI in Tanzania. The objective of this study is to resurvey these intervening factors, and using the method of logical analysis derive their course-effect relationship in order to propose the direction towards improving the situation.

\section{THE SURVEY}

In order to establish the preponderance among factors which are the stumbling blocks towards effective use of e-Leaning in Tanzanian HLIs, three research instruments were used to collect data. These are the questionnaires, interviews, and focus group discussions.

A total of 18-questions in a structured questionnaire was designed with the objective to elicit the major obstacles underlying the implementation of online learning in HLIs in Tanzania and specifically UDOM. The respondents were randomly selected from six colleges to fill the questionnaires. A total of 340 questionnaires were filled. Furthermore; 10 respondents were interviewed. Gathered responses were statistically analyzed using descriptive statistics like frequencies, percentage and graphs, with the help of Statistical Package for Social Science (SPSS). Furthermore focus group discussions were conducted among professionals to find out their opinion regarding the preponderance of factors that contribute to underutilization of e-Leaning in HLIs.

\section{RESULTS AND DISCUSSION}

Several factors contributing to the backwardness of online learning implementation at UDOM were identified and grouped without a base criterion. The factors that were mentioned by respondents include:

- Lack of equipment, management support, poor policy, insufficient financial resources and unstable power.

- Lack of awareness on online learning, high cost of Internet and low bandwidth.

- Lack of technical personnel.

Fig. 2 depicts the percentage of respondents per categories of the factors that hinder the implementation of online eLearning at UDOM.

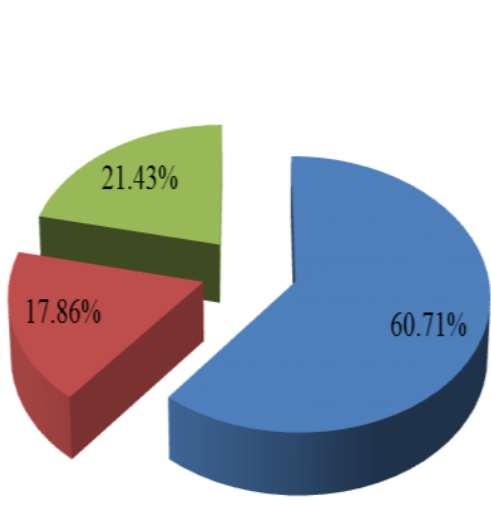

- Insufficient/lack of equipment, management/government support, poor policy, insufficient financial resources and unstable supply of electricity

- Lack of information (awareness on on-line learning issues) to instructors and students, high cost of Internet and low bandwidth

- Lack of expertise technological personnel

Fig. 2: Response on challenges facing online learning implementation at UDOM

\subsection{Lack of equipment and management support, poor policy, unstable supply of electricity and insufficient financial resources}

As depicted in Fig. 2, lack of equipment and management support, poor policy, unstable supply of electricity and insufficient financial resources account for $60.71 \%$ among all factors. These factors were reported to play a prominent role in hindering the implementation of online learning at UDOM 
in particular and Tanzania in general. However, logically, these factors are a result of lack of awareness on the importance and the usefulness of ICTs in education.

\subsection{Lack of expertise and technical personnel}

This accounts for $21.43 \%$ among all factors, as depicted in Fig 2. The more the technical expertise supports then the higher the chance to for implementation of online learning program. Since the online learning is often significantly enhanced by, and supported through technical innovation its importance is obvious. Most of the technical staff (system administrators) are not well versed and sufficiently specialized to be reliable for the job they are supposed to undertake. Again looked in closer from logical perspective, lack of technical expertise is the result of lack of awareness on the part of management.

\subsection{Lack of awareness and high cost of Internet and low bandwidth}

This accounts for $17.86 \%$ among all of the factors. Most respondents showed that they were aware of the presence of eLeaning systems at UDOM. This was found out through the question that asked respondent if they were aware of availability of e-Leaning environments such as MOODLE at UDOM. Although a substantial number of respondents indicated to be aware of the presence of e-Leaning system at UDOM as reflected in Table 1 the same people responded that they were not regular users of the system. They contend that connectivity was almost non existent and this was the main reason why they did not bother themselves with the system.

However, members of the management were not aware of this state of affairs. There was a complete divorce of views between these groups. It logically shows that the management is aware of e-Leaning as concept but not as a pragmatic posture that they should adopt and sustain while ensuring that the members of staff and students were utilizing it.

Table 1: Statistics about the presence of LMS at UDOM

\begin{tabular}{lcccl}
\hline \hline & Frequency & Percent & $\begin{array}{l}\text { Valid } \\
\text { Percent }\end{array}$ & $\begin{array}{l}\text { Cumulative } \\
\text { Percent }\end{array}$ \\
\hline Yes & 161 & 47.4 & 47.35 & 47.35 \\
No & 179 & 52.6 & 52.65 & 100.00 \\
Total & 340 & 100.0 & 100.00 &
\end{tabular}

Internet connection at UDOM is often down for some hours, sometimes days. The Internet has positive influences on learning as it is a source of information, provides independent and individualized learning, gives in-depth understanding and improves learners' motivation [12]. Hence if there is problem with the Internet then, those advantages of the Internet are impossible to achieve. Not only that but also limitations on the bandwidth reflect to some problem since sometimes the system is not accessible due to limitation on the bandwidth. This can be proved by Fig. 3 which shows the response from respondents of the question "How can you rate the availability of Internet connectivity in your teaching/learning/working place?" From this question it has been shown that $83.2 \%$ of all respondents said the Internet is available but with low speed, $15.6 \%$ have said that the Internet is not available at all while only $1.2 \%$ has said the availability of Internet is excellent. This can be summarized by Fig 3 .

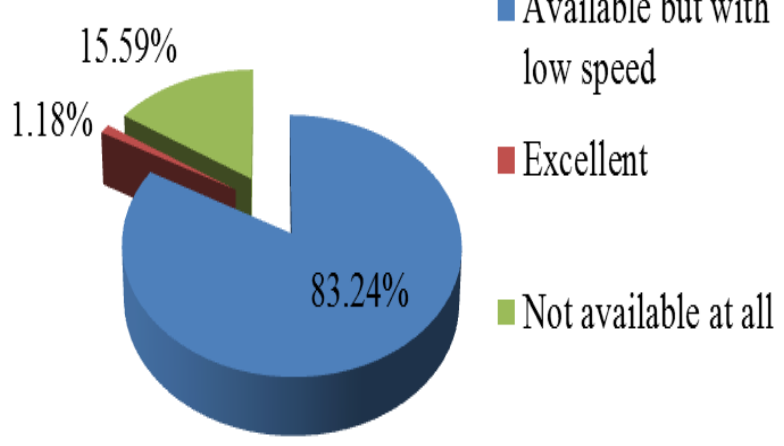

Fig. 3: Response on the rate of Internet connectivity in their teaching/learning place.

\section{CONCLUSION AND RECOMMENDATIONS}

The objective of the study was to revisit the challenges facing the implementations of online learning programs for higher learning institutions in Tanzania and establish the cause-effect and preponderance relationship among them using the method of logical analysis.

It was found that, the various challenges which are facing the implementations of online learning on higher learning institutions include; lack of equipment, lack of management support, poor policy and financial resources and unstable supply of electricity which contributes $61.77 \%$ among the all factors. This seems to agree with [4], [5] and [9].

Other factors include lack of awareness on online learning, high cost of Internet and low bandwidth which has contributed around $20.80 \%$ among all factors.

Further, lack of technical personnel was pointed out by some of the respondents as the factor that has contributed to the backwardness of online implementation at UDOM, scoring $17.43 \%$ among the all factors. This seems to agree with [4], [5] and [6].

Using the method of logical analysis, the researchers derived a relationship diagram among intervening factors as presented in Figure 4. 

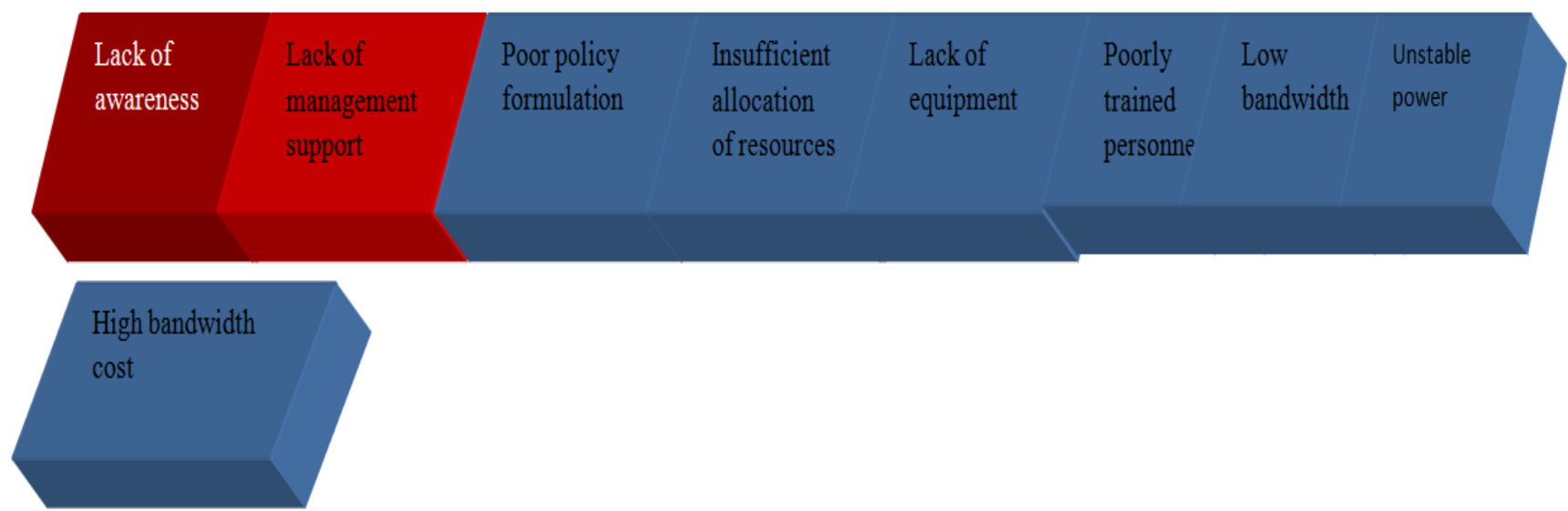

Figure 4: Preponderance among the intervening factors

Among all intervening factors, lack of awareness of the benefits of online learning approach is the source of lack of management support which results into poor policy formulation. As a consequence, insufficient allocation of financial resources, lack of equipment, poorly trained personnel; low bandwidth and unstable power have been left without sufficient effort to tackle them. High cost of bandwidth is the only factor outside of the cascading effect of the lack of awareness. It can be said that with sufficient awareness of the benefits associated with online leaning benefits, even the bandwidth cost is a surmountable challenge.

The findings of this study will help UDOM and other higher learning institutions to understand the factors which hinder the implementation of online learning and focus the effort on the core contributor.

Having established this preponderance, and having rankled lack of awareness as the core obstacle, the next challenge would be to research on effective ways to stimulate sufficient awareness among stakeholders. That is to discover mechanisms which may arouse the zeal to pursue online learning among politicians, investors, parents and students.

\section{REFERENCES}

[1] Chitanana, L., Makaza, D. and Madzima, K. "The current state of e-learning at universities in Zimbabwe: Opportunities and challenges", International Journal of Education and Development using Information and Communication Technology (IJEDICT), Vol. 4, Issue 2, (2008) pp. 5-15.

[2] UNESCO, "Policy Paper for Change and Development in Higher Education", Printed in France, (1995).

[3] Swarts, P. and Wachira, M. E., "TANZANIA: ICT IN EDUCATION SITUATIONAL ANALYSIS", July, 2010, unpublished.

[4] Rais, M. A. and Hashim, Y., "The Experience of the ELearning Implementation at the Universiti Pendidikan Sultan Idris, Malaysia", Malaysian Online Journal of Instructional Technology (MOJIT), 2004.
[5] Abdul Razak, Z., Amin Embi, M. and Nordin, M.N., "eLearning Governance in Malaysian Higher Education Institutions", International Lifelong Learning Conference (ICLL), 2011.

[6] Hussin, S., Amin Embi, M. and Atan, H., "e-Learning Training in Malaysian Institutions of Higher Learning", Internet Journal of e-Language Learning and Teaching (iJeLLT), 2011.

[7] Unwin, T., "Survey of e-Learning in Africa Based on a Questionnaire Survey of People on the e-Learning Africa Database in 2007", 2008.

[8] Gunga, O. S. and Ricketts, W. I.," Facing the challenges of e-learning initiatives in African universities", British Journal of Educational Technology, Volume 38, Issue 5, 2007, pp 896-906.

[9] Lujara, K.S., "Development of e-Learning Content and Delivery for Self Learning Environment: Case of Selected Rural Secondary Schools in Tanzania", Blekinge Institute of Technology, Sweden, 2008.

[10] Waits, T. and Lewis, L. "Distance education at degree granting postsecondary institutions:2000-2001", Institute of education science, National center for education statistics, Vol. 5, Issue 3, 2004, [http://nces.ed.gov/programs/quarterly/vol_5/5_3/4_4.as] , retrieved on 12/02/2012.

[11] Tedre, M., Ngumbuke, F. and Kemppainen, J., "Infrastructure, Human Capacity, and High Hopes: A Decade of Development of e-Learning in a Tanzanian HEI", Revista de Universidad y Sociedad del Conocimiento, Vol. 7, No. 1, 2010.

[12] Goi, L. C. and Ng, Y. P.,"E-learning in Malaysia: Success factors in implementing e-learning program", International Journal of Teaching and Learning in Higher Education, Vol. 20, No. 2, 2009,pp 237-246. 